ISSN 1659-3316

Especial: Profesores de Estudios Generales investigan

Dossier: El Quehacer de las Humanidades: Acción Social, Investigación y Metodologías e Innovación Tecnológica en la Docencia

\title{
La Acción Social y las Humanidades en la Universidad de Costa Rica
}

\author{
Bernardo Castillo Gaitán \\ Universidad de Costa Rica, Costa Rica \\ berantcg@gmail.com \\ https://orcid.org/0000-0003-2467-2349
}

Recibido: 13 de noviembre de 2019

Aceptado: 29 de enero de 2020

Resumen: La presente reflexión pretende establecer la relación que existe entre la Acción Social, que es una actividad propia de la Universidad de Costa Rica, con su manera de ser, excelencia o carácter; que no es más que el Humanismo. El texto se compone de cuatro subtemas: algunos aspectos la Universidad de Costa Rica, del concepto de Acción Social, definir el humanismo y relacionar la Acción Social y el Humanismo en la Universidad de Costa Rica.

Palabras Claves: Universidad; Acción Social; sociedad; humanismo.

\section{Social Action and the Humanities in the University of Costa Rica}

Abstrac: This reflection aims to establish the relationship between Social Action, which is an activity of the University of Costa Rica, with its way of being, excellence or character; that is nothing more than Humanism. The text consists of four subthemes: some aspects about the University of Costa Rica, about the concept of

\section{(c) (i) (2) (2)}

La Revista Estudios es editada por la Universidad de Costa Rica y se distribuye bajo una Licencia Creative Commons Atribución-NoComercial-CompartirIgual 3.0 Costa Rica. Para más información envíe un mensaje a 


\section{Especial: Profesores de Estudios Generales investigan}

Social Action, define humanism and relate Social Action and Humanism at the University of Costa Rica.

Keywords: University: Social Work; society; humanism.

\section{Presentación}

Definir qué es la Universidad de Costa Rica es una tarea que se puede realizar recorriendo sus edificios, observando a las personas de transitan por ella, contemplando las obras de arte expuestas permanentemente en diferentes lugares de la Ciudad Universitaria, pero también encontrando alguna frase de sus fundadores, por tal razón: "La Universidad es, en efecto, la garantía institucional de una tarea a la que el hombre no ha renunciado aun afortunadamente: la de no contentarse con subsistir, sino intentar dar un sentido a la existencia". Esta definición inventada por Don Abelardo Bonilla y eternizada en una de las paredes del Auditorio de la Escuela de Estudios Generales, demuestra la dinámica de una institución que fue hecha para pensar y actuar con un gran sentido humano.

Lo dicho por Don Abelardo, es ampliado en el artículo 1 del Estatuto Orgánico donde se expresa que:

“La Universidad de Costa Rica es una institución de educación superior y cultura, autónoma constitucionalmente y democrática, constituida por una comunidad de profesores y profesoras, estudiantes, funcionarias y funcionarios administrativos, dedicada a la enseñanza, la investigación, la Acción Social, el estudio, la meditación, la creación artística y la difusión del conocimiento".

Los textos anteriores evidencian que la Universidad de Costa Rica fue pensada para la Acción Social, tanto por sus fundadores como por su legislación. La "UCR", como se conoce coloquialmente, es en sí misma Acción para y en la sociedad; procurando cada día dar sentido a la existencia de las personas que se relacionan de una u otra manera con ella. Esta tarea la institución la realiza por

\section{(c) (i) (2)(2)}

La Revista Estudios es editada por la Universidad de Costa Rica y se distribuye bajo una Licencia Creative Commons Atribución-NoComercial-CompartirIgual 3.0 Costa Rica. Para más información envíe un mensaje a 


\section{Especial: Profesores de Estudios Generales investigan}

medio de su carácter humanista cultivando y desarrollando todas aquellas actividades propias del ser humano resumidas en lo que es la cultura, esto queda evidenciado por medio del Decreto Legislativo 8098 del 12 de marzo del 2001 al declararse a la "Universidad de Costa Rica como institución benemérita de la Educación y la cultura costarricense”. Dicha declaratoria refuerza la afirmación antes dicha que la Universidad de Costa Rica, nace como Acción Social contribuyendo para que la sociedad costarricense sea más justa, equilibrada, equitativa, pensante, prudente y conviviente.

\section{La Acción Social}

Se puede decir que la Acción Social, es la actualización de la Universidad de Costa Rica en un lugar. Actualización es, estar presente desde sí mismo como real (Gracia, 1986). La actualidad es la esencia de la intelección, en el caso que nos ocupa, la Acción Social, es la presencia o actualidad de la Universidad de Costa Rica en la sociedad en general y por opción de sus principios y de su ser humanista, en aquellos lugares donde se dificulta hacer experiencia de sociedad, debido a los diversos tipos de condiciones que ocultan o reprimen el poder que tiene la dignidad humana.

La dinámica o el movimiento que se sigue de la Acción Social, parte de uno de los pilares esenciales de la Universidad Pública, la autonomía. Estar presente en un lugar y en una situación con la única intensión de devolver su dignidad, sin más. Sin una ideología política, social o económica. La única razón, es la humanidad. La sociabilidad, otra manera de decir Acción Social, da mayor autonomía entre la acción y humanidad. El ser humano puede intervenir en la estructura de la acción. La habitud, es una acción con sentido, es el modo de tratar las cosas, un modo concreto de relacionarse con las cosas. De lo anterior se afirma que la Acción Social es la manera de ser de la Universidad de Costa Rica en un lugar, es este caso en la sociedad.

\section{(c) (i) (9) (2)}

La Revista Estudios es editada por la Universidad de Costa Rica y se distribuye bajo una Licencia Creative Commons Atribución-NoComercial-CompartirIgual 3.0 Costa Rica. Para más información envíe un mensaje a revistaestudios.eeg@ucr.ac.cr. 
Especial: Profesores de Estudios Generales investigan

Al estar confirmada por personas, la Universidad de Costa Rica es un ser en el mundo, que se relaciona con los demás. El trato con los demás, la reciprocidad, el diálogo, la vida social, ha permitido que se formen numerosos grupos, asociaciones, instituciones económicas, sociales, culturales, recreativas deportivas, profesionales y políticas El equilibrio entre la vida privada del ciudadano, la vida social y los grupos privados, contribuirá a afirmar la personalidad y a desarrollar la convivencia necesaria para satisfacer los derechos y obligaciones de la vida social. Con la Acción Social, la Universidad de Costa Rica, reconoce que como individuo particular no puede alcanzar los fines comunes a causa de las limitaciones de su propia individualidad, necesita de la colaboración de otros para que, enriquecido con su ayuda, pueda superar los propios límites y abrirse la universalidad del conocimiento.

\section{Humanismo}

Por humanismo se entiende el modo de ejercer la actualidad de ser humano en un lugar. Es decir cuando las actividades como el arte, la literatura, la educación y la cultura en general, tienen al ser humano como su medida para ser valoradas. Con el humanismo toda actividad se vuelta trascendental como edificación de la dignidad del otro.

Se definen como el camino para realizar una labor a favor de la humanidad. En el caso de la acción que la Universidad de Costa Rica realiza, se trata de los valores y virtudes que motivan trabajar por la construcción de una institución preocupada por la formación integral de los estudiantes. Virtudes que permiten distinguir, diferenciar o discernir, con una visión clara y objetiva, las diversas situaciones de la realidad.

En el Humanismo la verdad, como línea de acción, tiene como objetivo el cumplimiento de lo que se ha propuesto hacer. Se presenta como el desarrollo de la búsqueda continua de las causas y de los diversos puntos de vista que permitan 
Especial: Profesores de Estudios Generales investigan

conocer y responder de la mejor manera a la problemática social que está pasando en determinado momento, más allá de preguntar qué significado para la vida tiene una determinada situación.

En el Humanismo, la libertad, es la actitud humana que permite a las persona asumir responsabilidades y tomar decisiones sin ser obligada. Implica la capacidad de ser dueño de la propia voluntad, de disponer de sí mismo para ayudar a los demás. Con la libertad se asume la solidaridad, una actitud humana que no lleva a tomar y resolver los problemas de los demás como propios, sino a buscar y construir herramientas de aprendizajes que permitan estar preparados ante situaciones futuras que sean semejantes a las presentes.

La justicia es una condición esencial para el humanismo y se entiende como el sentido último del progreso y de la historia y el objetivo de todo ordenamiento político, es decir, armonía en las relaciones de igualdad, satisfacción de necesidades y tutela de derechos, la paz se convierte en la condición indispensable para la vivencia de los principios de dicha doctrina. En la justicia se sintetizan la verdad, y la libertad. Es la capacidad que todo ser humano tiene para ponerse de acuerdo en lo mínimo esencial (respeto a la dignidad humana, la convivencia, los derechos humanos), en el caso de la Universidad Católica de Costa Rica, estar de acuerdo en sacar adelante el proyecto educativo como comunidad universitaria.

Con el humanismo, se define la antropología desde el ser mismo de la persona. En este caso, el ser humano desde el punto de vista humanista es un ser que anticipa, vive en el futuro, está continuamente proyectado, transformado y adaptando la naturaleza. El ser humano vive en un mundo cultural transformando la naturaleza por medio de la inteligencia y el proyecto, siempre desea transformar el medio. Lo que se llama proyecto es dar valor a la naturaleza, es añadir valor a través del trabajo. El mundo de la cultura es el mundo del valor, se añade valor a la naturaleza. Otra cosa es que la inteligencia no sea capaz de transformar el 
Especial: Profesores de Estudios Generales investigan

medio. En todo proyecto hay un momento de valoración, hay otro memento que se llama praxis o realización del proyecto, esto es lo que debo hacer, promover valores en sí mismo.

\section{La Acción Social y el Humanismo en la Universidad de Costa Rica}

Para la Universidad de Costa Rica, la Acción Social, además de ser, una dedicación, atención y esfuerzo, es uno de los principios orientadores del que hacer universitario que se consigue al:

"estudiar los problemas de la comunidad y participar en proyectos tendientes al pleno desarrollo de los recursos humanos, en función de un plan integral, destinado a formar un régimen social justo, que elimine las causas que producen la ignorancia y la miseria, así como a evitar la indebida explotación de los recursos del país" (Estatuto Orgánico Art. 3, h).

Las humanidades en la Universidad de Costa Rica han sido pensadas para fortalecer rasgos esenciales del ser humano para el ejercicio de la humanidad en la sociedad. Los Cursos Integrados de Humanidades (conocidos por todos como humanidades), ya sean en su opción regular o seminario participativo van conformado y formando las relaciones humanas que se expresan en la comunicación y el lenguaje; entrenan la actividad humana de pensar, ubicando al estudiante en una visión filosófica humanista o si quiere una forma de responder al contexto histórico social por medio de más preguntas.

Las Humanidades, al ser parte de la formación inicial y permanente del estudiante de la UCR, permiten la conformación de la mentalidad histórica la cual es principio para valorar la identidad, el presente y el destino de los pueblos (Historia de la Cultura). Las humanidades no pueden dejar de un lado, la capacidad y el deseo de búsqueda que tiene el ser humano, por ello ofrecen las bases científicas de esa búsqueda; responder a una inquietud que se puede convertir en obstáculo para crecer en dignidad.

\section{(c) (i) (2)}

La Revista Estudios es editada por la Universidad de Costa Rica y se distribuye bajo una Licencia Creative Commons Atribución-NoComercial-CompartirIgual 3.0 Costa Rica. Para más información envíe un mensaje a 
Especial: Profesores de Estudios Generales investigan

En conclusión por Acción Social se entiende un movimiento, un hecho, un acto orientado a la transformación de la sociedad, a mejorar las condiciones humanas, sociales, económicas, políticas y ambientales del lugar tomando en cuenta las capacidades de las personas e integrándolas con el conocimiento ofrecido por la Universidad de Costa Rica. La razón de ser de la Acción Social de la UCR, es forjar vínculos sociales expresando el sentido de equidad, que es el descubrimiento y respeto de las diferentes capacidades que tienen las personas.

El humanismo de la Universidad de Costa Rica, se hace realidad visible en la Acción Social demostrándose en: la devolución de la inversión económica que la sociedad invierte en la institución, en la generación de una opinión pública libre odiosas exclusiones de cualquier tipo, en el impulso del pensamiento crítico que genera cambios sociales auto- gestionados que traen consigo los siguientes efectos: el fortalecimiento de la identidad de las comunidades, en la educación para que las comunidades tengan la capacidad de resolver sus problemas, en la visibilización a las sociedades marginadas, en el aprendizaje social por parte de la comunidad universitaria a partir de la vivencia de la pobreza, en el fortalecimiento del carácter humanista de la UCR, en la educación de una racionalidad que no imponga conocimientos con el fin de crear dependencia, sino una racionalidad que toma en cuenta el reconocimiento, la cultura propia del lugar que provoque el desarrollo de experiencias de dignidad humana que antes no existían y en la transformación del quehacer universitario cuestionando el concepto de universidad que le permite, a la institución no olvidarse que su principal tarea es elevar la dignidad humana de todos los que a ella acuden.

\section{(c) (i) (-)}

La Revista Estudios es editada por la Universidad de Costa Rica y se distribuye bajo una Licencia Creative Commons Atribución-NoComercial-CompartirIgual 3.0 Costa Rica. Para más información envíe un mensaje a 
ISSN 1659-3316

\section{Bibliografía}

Asamblea Legislativa de Costa Rica. (2001). Decreto Legislativo 8098.

Gracia. D. (1986). Voluntad de Verdad. Para leer a Zubiri. Calabria.: Editorial Labor S.A.

Consejo Universitario. (2005). Estatuto Orgánico de la Universidad de Costa Rica 